\title{
Evaluasi Pelaksanaan Kelas Ibu Hamil Di Wilayah Kerja Puskesmas Madapangga Kabupaten Bima Tahun 2019
}

\author{
Sukmawati \\ Poltekkes Kemenkes Mataram Jurusan Keperawatan \\ sukmawatinukman26@gmail.com
}

Received: 26 April 2021; Revised: 16 July 2021; Accepted: 13 August 2021

DOI: http://dx.doi.org/10.37905/aksara.7.3.937-946.2021

\begin{abstract}
ABSTRAK
Kelas ibu hamil merupakan salah satu kegiatan penting dalam penerapan buku KIA, berfungsi untuk mempersiapkan ibu hamil menghadapi persalinan yang aman dan nyaman. Tujuan penelitian untuk mengetahui pelaksanaan evaluasi kelas ibu hamil di wilayah kerja Puskesmas Madapangga. Desain penelitian deskriptif korelasi dan ditinjau dari segi waktu bersifat cross sectional. Populasi adalah semua ibu hamil yang mengikuti kelas ibu bulan Agustus-November 2019 di wilayah kerja Puskesmas Madapangga berjumlah 60 orang. Cara pengambilan sampel secara total sampel. Pengumpulan data menggunakan kuesioner. Analisa data menggunakan uji chisquare test. Penelitian disimpulkan ada hubungan pengetahuan dengan persiapan pelaksanaan kelas ibu hamil P-Value $\alpha=0.003<0.05$, tidak ada hubungan sikap ibu terhadap pelaksanaan Kelas ibu hamil P-Value $\alpha=0.008>0.05$ dan tidak ada hubungan antara sarana dan prasarana dengan persiapan pelaksanaan kelasibu hamil P-Value $\alpha=0.016>0.05$

Kata Kunci : Pengetahuan, Sikap, Sarana dan prasarana, pelaksanaan kelas ibu hamil
\end{abstract}

\begin{abstract}
Class for pregnant women is one of the important activities in the application of the KIA handbook, which serves to prepare pregnant women for a safe and comfortable delivery. The purpose of the study was to determine the implementation of the evaluation of pregnant women in the working area of the Madapangga Public Health Center. Correlation descriptive research design and in terms of time is cross sectional. The population is all pregnant women who take part in the mother's class in August-November 2019 in the working area of the Madapangga Health Center totaling 60 people. The sampling method is the total sample. Collecting data using a questionnaire. Data analysis using chi-square test. The study concluded that there was a relationship between knowledge and preparation for the implementation of the P-Value class for pregnant women $=0.003<0.05$, there was no relationship between the mother's attitude towards the implementation of the P-Value class for pregnant women $=0.008>0.05$ and there was no relationship between facilities and infrastructure and preparation for implementation. class of pregnant women $\mathrm{P}$-Value $=0.016>0.05$
\end{abstract}

Keywords: Knowledge, Attitude, Facilities and infrastructure, implementation of class for pregnant women 


\section{PENDAHULUAN}

Program Pembangunan kesehatan di Indonesia dewasa ini masih diprioritaskan pada upaya peningkatan derajat kesehatan ibu dan anak, terutama pada kelompok yang paling rentan kesehatan yaitu ibu hamil, bersalin dan bayi pada masa perinatal. Hal ini ditandai dengan tingginya Angka Kematian Ibu (AKI) dan Angka Kematian Bayi (AKB) (Naharani, Siswati, \& Fatkhiyah, 2018)

Kelas ibu merupakan salah satu kegiatan penting dalam penerapan buku KIA di masyarakat sebagai upaya pembelajaran ibu, suami, dan keluarga agar memahami buku KIA melalui metode kegiatan belajar bersama dalam kelas yang difasilitasi oleh petugas kesehatan untuk mempersiapkan ibu hamil menghadapi persalinan yang aman dan nyaman. Beberapa kegiatan seperti senam ibu hamil, latihan pernafasan pada persalinan dan cara menyusui bayi juga diberikan, hal ini meningkatkan minat ibu-ibu hamil untuk mengikuti kelas ibu hamil tersebut (Lapalulu, 2018). Kelas ibu hamil merupakan salah satu program kesehatan yang diharapkan turut berperan dalam menurunkan angka kesakitan dan kematian akibat kehamilan, persalinan dan nifas. Kelas ibu hamil merupakan sarana belajar bersama yang perlu diikuti oleh ibu hamil agar memperoleh pengetahuan yang cukup sehingga dapat mencegah komplikasi dan meningkatkan cakupan K1, K4 serta melakukan persalinan pada tenaga kesehatan (Retnowati \& Sulidah, 2018)

Pada dasarnya kelas ibu hamil merupakan proses pembelajaran (Kemenkes, 2016). Suatu keberhasilan pelatihan/pembelajaran dapat dilihat dari input, proses, luaran, dampak, evaluasi dan lingkungan. Menurut Notoatmodjo (2009) terdapat empat kelompok faktor yang berpengaruh terhadap keberhasilan sebuah pelatihan/pembelajaran yaitu, (1) faktor materi/hal yang dipelajari, (2) lingkungan fisik antar lain, suhu, kelembaban udara, kondisi tempat belajar dan lingkungan sosial yakni manusia dengan segala interaksinya, (3) instrumental yang terdiri dari perangkat keras seperti perlengkapan belajar, alat peraga dan perangkat lunak seperti kurikulum, pengajar, serta metode belajar, dan (4) kondisi individual subjek belajar yakni kondisi fisiologis seperti panca indra dan status gizi serta kondisi psikologis misalnya intelegensi, pengamatan, daya tangkap dan ingatan (Fuada \& Setyawati, 2016)

Hasil dari beberapa studi mengungkapkan bahwa penyebab utama kematian ibu dapat dikelompokkan menjadi penyebab langsung dan penyebab tidak langsung. Penyebab langsung kematian ibu kurang lebih $90 \%$ disebabkan oleh seputar persalinan, dan kematian tersebut terjadi karena komplikasi, sedangkan penyebab tidak langsung antara lain di sebabkan oleh sosial ekonomi, pendidikan, kedudukan dan peranan wanita, sosial budaya, dan transportasi. Hal yang dapat mendukung disebabkan ibu terlalu tua untuk mempunyai anak, ibu terlalu banyak melahirkan, ibu terlalu sering/rapat jarak melahirkan, terlambat mengenal tanda bahaya dan mengambil keputusan, terlambat membawa dan mencapai fasilitas kesehatan, serta terlambat mendapat pertolongan di fasilitas kesehatan (R. Oktaviance. S, 2016).

Kemenkes RI, 2016 adanya kelas ibu hamil hasil diharapkan adanya interaksi dan berbagi pengalaman antar peserta (ibu hamil) dengan ibu hamil, ibu hamil dengan bidan/tenaga kesehatan tentang kehamilan, perubahan tubuh dan keluhan selama kehamilan, perawatan kehamilan, persalinan, perawatan nifas, perawatan bayi, mitos atau kepercayaan atau ada istiadat setempat, penyakit menular dan akte kelahiran. Selain itu juga diharapkan ibu hamil dapat memahami kehamilan, perawatan kehamilan, 
persalinan meliputi tanda-tanda persalinan, perawatan nifas, seta KB pasca persalinan (Naharani et al., 2018)

Guna mengatasi permasalahan di atas, sejak tahun 2006 direncanakan metode pembelajaran kelas ibu hamil. Kegiatan yang direncanakan adalah pembahasan materi Buku KIA dalam bentuk tatap muka dalam kelompok yang diikuti diskusi dan tukar pengalaman antara ibu-ibu hamil dan petugas kesehatan. Kegiatan kelompok belajar ini diberi nama "Kelas Ibu Hamil". Tujuan pelaksanaan kelas ibu adalah untuk meningkatkan pengetahuan, merubah sikap dan perilaku ibu agar memahami tentang kehamilan, perubahan tubuh dan keluhan selama kehamilan, perawatan kehamilan, persalinan, perawatan nifas, perawatan bayi baru lahir, mitos/kepercayaan/adat istiadat setempat, penyakit menular dan akte kelahiran. Dengan adanya kegiatan kelas ibu tersebut diharapkan dapat menurunkan AKI dan AKB (Retnowati \& Sulidah, 2018)

Upaya Pemerintah untuk mempercepat penurunan kematian ibu dan bayi melalui peningkatan pengetahuan dan perubahan perilaku ibu dan keluarga. Peningkatan pengetahuan dan perubahan perilaku ini diharapkan kesadaran terhadap pentingnya kesehatan selama kehamilan menjadi meningkat. Program yang diselenggarakan oleh Kementerian Kesehatan untuk mendukung langkah tersebut adalah Kelas Ibu Hamil Kegiatan kelas ibu hamil menggunakan metode pembelajaran salah satunya dengan pembahasan materi Buku KIA. Penggunaan Buku KIA diharapkan dapat meningkatkan kualitas pelayanan Kesehatan Ibu dan Anak serta gizi sehingga salah satu tujuan pembangunan nasional yaitu penurunan AKI dan AKB dapat tercapai(Naharani et al., 2018)

Tujuan penelitian ini untuk mengevaluasi pelaksanaan kelas ibu hamil di Wilayah Kerja Puskesmas Madapangga Kabupaten Bima Tahun 2019?

\section{METODE}

Desain penelitian deskriptif korelasi dan ditinjau dari segi waktu bersifat cross sectional dimana peneliti melakukan observasi atau pengukuran variabel sesaat artinya subyek diobservasi satu kali saja dan pengukuran variabel. Populasi penelitian adalah semua ibu hamil yang mengikuti kelas ibu pada bulan Agustus s/d November 2019 di wilayah kerja Puskesmas Madapangga berjumlah 60 orang. Cara pengambilan sampel secara total sampel.

Cara pengumpulan data menggunakan kuesioner yang berisikan tentang pengetahuan dan sikap ibu hamil, sarana dan prasarana pelaksanaan ibu hamil, persiapan dan pelaksanaan ibu hamil, pelayanan ANC dan kesiapan ibu pada saat masa nifas dan kehadiran ibu pada saat pelaksanaan kelas ibu hamil. Analisa data menggunakan uji chisquare test.

\section{HASIL DAN PEMBAHASAN \\ HASIL PENELITIAN}

Pada bab ini akan disajikan hasil penelitian dan analisa data yang telah di temukan selama penelitian dilaksanakan. Penelitian ini dilaksanakan pada 15 Agustus sampai dengan 1 November 2019 di Wilayah Kerja Puskesmas Madapangga Kecamatan Madapangga Kabupaten Bima, yaitu di Desa Woro, Desa Ndano, Desa Campa, Desa Ncandi dan Desa Bolo. 
1. Gambaran Pelaksanaan kelas Ibu Hamil

a. Pengetahuan Ibu Hamil tentang Pelaksanaan Kelas Ibu Hamil

\section{Tabel 1}

Distribusi Pengetahuan Ibu Hamil tentang Pelaksanaan Kelas Ibu Hamil di Wilayah Kerja Puskesmas MadapanggaKabupaten Bima tanggal 15 Agustus s/d 1 November 2019

\begin{tabular}{|l|l|c|c|}
\hline No & \multicolumn{1}{|c|}{ Pengetahuan } & $\mathrm{n}$ & $\%$ \\
\hline 1 & Baik sekali & 20 & 33.3 \\
\hline 2 & Baik & 19 & 31.7 \\
\hline 3 & Cukup baik & 18 & 30 \\
\hline 4 & Kurang & 3 & 5 \\
\hline 5 & Total & 60 & 100 \\
\hline
\end{tabular}

Tabel 1 menunjukkan bahwa pengetahuan ibu hamil tentang kelas ibu hamil terbanyak baik sekali sebanyak 20 orang (33.3\%)

b. Sikap Ibu Hamil tentang Pelaksanaan Kelas Ibu Hamil

\section{Tabel 2}

Distribusi Sikap Ibu Hamil tentang Pelaksanaan Kelas Ibu Hamil di Wilayah Kerja Puskesmas Madapangga Kabupaten Bima tanggal 15 Agustus s/d 1 November 2019

\begin{tabular}{|l|l|c|c|}
\hline No & \multicolumn{1}{|c|}{ Sikap } & n & $\%$ \\
\hline 1 & Baik sekali & 18 & 30 \\
\hline 2 & Baik & 23 & 28.3 \\
\hline 3 & Cukup baik & 16 & 26.7 \\
\hline 4 & Kurang & 2 & 5 \\
\hline 5 & Total & 60 & 100 \\
\hline
\end{tabular}

Tabel 2 menunjukkan bahwa sikap ibu hamil tentang pelaksanaan kelas ibu hamil terbanyak baik sebanyak 22 orang $(28.3 \%)$

\section{c. Sarana dan Prasarana Pelaksanaan Kelas Ibu Hamil}

Tabel 3

Distribusi Sarana dan Prasarana Pelaksanaan Kelas Ibu Hamil di Wilayah Kerja Puskesmas Madapangga Kabupaten Bima tanggal 15 Agustus s/d 1 November 2019

\begin{tabular}{|l|l|c|c|}
\hline No & \multicolumn{1}{|c|}{ Sarana dan Prasarana } & n & $\%$ \\
\hline 1 & Baik & 42 & 70 \\
\hline 2 & Cukup & 18 & 30 \\
\hline 3 & Total & 60 & 100 \\
\hline
\end{tabular}

Tabel 3 menunjukkan bahwa responden mengatakan sarana dan prasarana pelaksanaan kelas ibu hamil baik sebanyak 42 orang (70 \%) 
d. Pelaksanaan Kelas Ibu Hamil

Tabel 4

Distribusi Pelaksanaan Kelas Ibu Hamil di Wilayah Kerja Puskesmas Madapangga Kabupaten Bima tanggal 15 Agustus s/d 1 November 2019

\begin{tabular}{|l|l|c|c|}
\hline No & Pelaksanaan Kelas Ibu Hamil & n & $\%$ \\
\hline 1 & Baik & 51 & 85 \\
\hline 2 & Cukup & 9 & 15 \\
\hline 3 & Total & 60 & 100 \\
\hline
\end{tabular}

Tabel 4 menunjukkan bahwa pelaksanaan kelas ibu hamil baik sebanyak 51 orang $(85 \%)$

\section{Analisis Bivariat}

\section{a. Analisis Pengetahuan ibu dengan pelaksanaan kelas ibu hamil}

\section{Tabel 5}

Analisis Pengetahuan ibu terhadap Persiapan Pelaksanaan kelas Ibu Hamil di Wilayah Kerja Puskesmas Madapangga Kabupaten Bima tanggal 15 Agustus s/d 1 November 2019

\begin{tabular}{|c|c|c|c|c|}
\hline \multirow[t]{2}{*}{$\begin{array}{c}\text { Pengetahuan } \\
\text { Ibu }\end{array}$} & \multicolumn{2}{|c|}{$\begin{array}{l}\text { Persiapan Pelaksanaan } \\
\text { Kelas Ibu Hamil }\end{array}$} & \multirow[t]{2}{*}{ Total } & \multirow[t]{2}{*}{$p$ value } \\
\hline & Baik & Cukup & & \\
\hline Sangat Baik & $20(100 \%)$ & 0 & $20(100 \%)$ & \multirow{5}{*}{0.003} \\
\hline Baik & $17(89.5 \%)$ & $2(10.5 \%)$ & $19(100 \%)$ & \\
\hline Cukup & $11(61.1 \%)$ & $7(38.9 \%)$ & $\begin{array}{c}18 \\
(100 \%)\end{array}$ & \\
\hline Kurang & $3(100 \%)$ & 0 & $3(100 \%)$ & \\
\hline Total & 51 & 9 & $60(100 \%)$ & \\
\hline
\end{tabular}

Pada tabel 5 menunjukkan bahwa pada persiapan pelaksanaan kelas ibu $20(100 \%)$ orang ibu memiliki pengetahuan baik sekali, dan pada persiapan pelaksanaan kelas ibu cukup tingkat pengetahuan ibu baik sekali sebanyak 0 orang ibu, dan pada persiapan pelaksanaan kelas ibu baik terdapat 17 orang ibu $(89.5 \%)$ memiliki pengetahuan baik dan persiapan pelaksanaan kelas ibu cukup 2 orang ibu (10.5\%) memiliki pengetahuan baik. Sedangkan pada persiapan pelaksanaan kelas ibu baik terdapat 11 orang ibu $(61.1 \%)$ memiliki pengetahuan cukup dan persiapan pelaksanaan kelas ibu cukup 7 orang ibu (38.9\%) memiliki pengetahuan cukup. pada persiapan pelaksanaan kelas ibu baik terdapat 3 orang ibu (100\%) memiliki pengetahuan kurang dan persiapan pelaksanaan kelas ibu cukup 0 orang ibu $(0 \%)$ memiliki pengetahuan kurang.

Hasil uji statistik chi-square test $P$-Value $\alpha=0.003$ dengan nilai $\alpha<$ 0.05 yang artinya ada hubungan yang signifikan antara pengetahuan ibu dengan persiapan pelaksanaan kelas ibu hamil 


\section{b. Analisis Sikap ibu dengan pelaksanaan kelas ibu hamil}

Tabel 6

Analisis Sikap Ibu terhadap Persiapan Pelaksanaan kelas Ibu Hamil di Wilayah Kerja Puskesmas Madapangga Kabupaten Bima tanggal 15 Agustus s/d 1 November 2019

\begin{tabular}{|c|c|c|c|c|}
\hline \multirow[t]{2}{*}{ Sikap Ibu } & \multicolumn{2}{|c|}{$\begin{array}{c}\text { Persiapan Pelaksanaan Kelas } \\
\text { Ibu Hamil }\end{array}$} & \multirow[t]{2}{*}{ Total } & \multirow[t]{2}{*}{$p$ value } \\
\hline & Baik & Cukup & & \\
\hline Baik Sekali & $18(100 \%)$ & 0 & $18(100 \%)$ & \multirow{5}{*}{0.008} \\
\hline Baik & $20(87 \%)$ & $3(13 \%)$ & $23(100 \%)$ & \\
\hline Cukup & $10(62.5 \%)$ & $6(37.5 \%)$ & $\begin{array}{c}16 \\
(100 \%)\end{array}$ & \\
\hline Kurang & $3(100 \%)$ & 0 & $3(100 \%)$ & \\
\hline Total & 51 & 9 & $60(100 \%)$ & \\
\hline
\end{tabular}

Pada tabel 6 menjelaskan bahwa pada persiapan pelaksanaan kelas ibu baik terdapat $18(100 \%)$ orang ibu memiliki sikap baik sekali, dan pada persiapan pelaksanaan kelas ibu cukup sikap ibu baik sekali sebanyak 0 orang ibu. Dan pada persiapan pelaksanaan kelas ibu baik terdapat 20 orang ibu ( $87 \%$ ) memiliki sikap baik dan persiapan pelaksanaan kelas ibu cukup 3 orang ibu (13\%) memiliki sikap baik. Sedangkan pada persiapan pelaksanaan kelas ibu baik terdapat 10 orang ibu (62.5\%) memiliki sikap cukup baik dan persiapan pelaksanaan kelas ibu cukup 6 orang ibu (37.5\%) memiliki sikap cukup baik. Pada persiapan pelaksanaan kelas ibu baik terdapat 3 orang ibu (100\%) memiliki sikap kurang baik dan persiapan pelaksanaan kelas ibu cukup 0 orang ibu (0\%) memiliki sikap kurang baik.

Hasil uji statistik chi-square test $P$-Value $\alpha=0.008$ dengan nilai $\alpha$ $>0.05$ yang artinya tidak ada hubungan signifikan antara sikap ibu dengan persiapan pelaksanaan kelas ibu hamil

\section{c. Analisis Sarana dan prasarana dengan pelaksanaan kelas ibu hamil} Tabel 6

Analisis Sarana dan Prasarana terhadap Persiapan Pelaksanaan kelas Ibu Hamil di Wilayah Kerja Puskesmas Madapangga Kabupaten Bima tanggal 15 Agustus s/d 1 November 2019

\begin{tabular}{|c|c|c|c|c|}
\hline \multirow{2}{*}{$\begin{array}{c}\text { Sarana dan } \\
\text { Prasarana }\end{array}$} & \multicolumn{2}{|c|}{$\begin{array}{c}\text { Persiapan Pelaksanaan Kelas } \\
\text { Ibu Hamil }\end{array}$} & \multirow{2}{*}{ P value } \\
\cline { 2 - 3 } & Baik & Cukup & & \\
\hline Baik & $39(92,9 \%)$ & $3(7.1 \%)$ & $\begin{array}{c}42 \\
(100 \%)\end{array}$ & \multirow{2}{*}{0.016} \\
\hline Cukup & $12(66.7)$ & $6(33.33 \%)$ & $\begin{array}{c}18 \\
(100 \%)\end{array}$ & \\
\hline Total & 51 & 9 & 60 & \\
\hline
\end{tabular}

Pada tabel 6 menunjukan bahwa pada persiapan pelaksanaan kelas ibu baik terdapat $39(92.9 \%)$ sarana dan prasarananya baik dan persiapan 
pelaksanaan kelas ibu cukup terdapat $3(7.1 \%)$ sarana dan prasarananya baik. Sedangkan pada persiapan pelaksanaan kelas ibu cukup sarana dan prasarana baik $12(66.7 \%)$ dan persiapan pelaksanaan kelas ibu cukup sarana dan prasarana cukup $6(33.3 \%)$

Hasil uji statistik chi-square test $P$-Value $\alpha=0.016$ dengan nilai $\alpha>$ 0.05 yang artinya tidak ada pengaruh yang signifikan antara sarana dan prasarana ibu dengan persiapan pelaksanaan kelas ibu hamil.

\section{PEMBAHASAN}

\section{Tingkat pengetahuan ibu dalam pelaksanaan kelas ibu hamil}

Hasil penelitian menunjukkan pengetahuan ibu masuk pada tingkat pengetahuan baik sekali yaitu 20 orang dan pengetahuan baik sebanyak 17 orang. Hasil uji statistik chi-square test P-Value $\alpha=0.003$ dengan nilai $\alpha<0.05$ yang artinya ada pengaruh yang signifikan antara pengetahuan ibu dengan persiapan pelaksanaan kelas ibu hamil.

Hasil penelitian ini sesuai dengan harapan pemerintah dalam tujuan pelaksanaan kelas ibu hamil dengan mengikuti kelas ibu hamil sebagai sarana untuk belajar bersama tentang kesehatan bagi ibu hamil yang bertujuan untuk meningkatkan pengetahuan, merubah sikap dan perilaku ibu agar memahami tentang kehamilan, perubahan tubuh dan keluhan selama hamil, perawatan kehamilan, persalinan, perawatan nifas, KB pasca persalinan, perawatan bayi baru lahir, mitos/kepercayaan/adat istiadat setempat, penyakit menular dan akte kelahiran (Kemenkes RI, 2014). Sedikit apapun informasi diperoleh ibu hamil pada kelas ibu hamil akan bermanfaat untuk persiapan psikologis serta mengurangi stress pada ibu hamil dalam menjalani masa kehamilan, persalinan, nifas dan perawatan bayi baru lahir Hasil penelitian ini sejalan dengan hasil penelitian Hastuti dkk (2010) bahwa pelatihan kelas ibu hamil efektif untuk meningkatkan pengetahuan ibu hamil mengenai perawatan seputar kehamilan, persalinan dan nifas, perawatan bayi baru lahir, KB pasca persalinan, termasuk penyakit menular dan akte kelahiran, sejalan pula dengan hasil penelitian Sumarni dkk (2005) ada beda pengetahuan dan sikap yang bermakna pada ibu hamil dalam menghadapi persalinan sebelum dan setelah pemberian kelas prenatal, senada dilakukan oleh Syafiq, dkk (2008) menyatakan bahwa kelas ibu hamil memiliki efek positif pada pengetahuan, sikap dan perilaku ibu berkaitan dengan perawatan kehamilan, persalinan, dan nifas, lebih banyak ibu melahirkan di dampingi bidan dibandingkan sebelum adanya kelas ilbu hamil di Lombok Tengah NTB (Ratmawati, 2018)

Kehamilan, persalinan, perawatan nifas, KB pasca persalinan, perawatan bayi baru lahir, mitos/kepercayaan/adat istiadat setempat, penyakit menular dan akte kelahiran. Bagi responden yang mendapat nilai dibawah rata-rata kemungkinan disebabkan kurang mendapatkan informasi dan kesalahan dalam menginterpretasikan informasi yang diperolehnya selama mengikuti kelas ibu hamil. Ini sesuai dengan pendapat Nanda (2005) bahwa yang mempengaruhi responden mendapatkan nilai terendah terkait dengan kurangnya pengetahuan (deficient knowledge) terutama disebabkan oleh kurang terpapar informasi dan 
kesalahan dalam menginterpretasikan informasi, selain faktor lain seperti kurang daya ingat, keterbatasan kognitif, kurang minat untuk belajar dan tidak familiar terhadap sumber informasi Peningkatan pengetahuan pada penelitian ini merupakan salah satu tolak ukur keberhasilan pelatihan kelas ibu hamil, yang di dalamnya terdapat kegiatan. Hal ini membuktikan bahwa dengan mengikuti kelas ibu hamil sangat bermanfaat bagi ibu dikarenakan pengetahuan yang diperoleh mengenai kehamilan, perubahan tubuh dan keluhan selama hamil, perawatan kehamilan, persalinan, perawatan nifas, KB pasca persalinan, perawatan bayi baru lahir dapat secara detail di terima pada kleas ibu.(Kemenkes RI, 2014)

\section{Sikap ibu dalam pelaksanaan kelas ibu hamil}

Hasil penelitian menggunakan uji statistik chi-square test P-Value $\alpha=0.008$ dengan nilai $\alpha>0.05$ yang artinya tidak ada pengaruh yang signifikan antara sikap ibu dengan persiapan pelaksanaan kelas ibu hamil. Hal ini sesuai dengan pendapat Wawan dan Dewi (2011) bahwa pengetahuan seseorang tentang suatu objek mengandung dua aspek yaitu aspek positif dan aspek negatif. Kedua aspek ini akan menentukan sikap seseorang, semakin banyak aspek positif dan objek yang diketahui, maka akan menimbulkan sikap semakin positif terhadap objek tertentu, dimana Sikap bukan dibawa sejak lahir melainkan dibentuk dan dipelajari sepanjang perkembangan orang tersebut dalam hubungan dengan objeknya. Sikap hanyalah kecenderungan untuk mengadakan tindakan terhadap suatu objek dengan suatu cara. Jadi, sikap adalah respons tertutup seseorang terhadap stimulus atau objek tertentu, yang sudah melibatkan faktor pendapat dan emosi yang bersangkutan (senang-tidak senang, setuju-tidak setuju, baik-tidak baik, dan sebagainya)

Menurut Maulana (2012), menyatakan bahwa sikap seseorang dapat berubah dengan diperolehnya tambahan informasi tentang objek tertentu, melalui persuasi serta tekanan dari kelompok sosialnya. Sikap dapat terbentuk dari adanya interaksi sosial yang dialami individu. Dalam penelitian ini sikap positif responden terbentuk dari adanya interaksi sosial yang dialami responden dengan tenaga kesehatan dan sesama peserta dalam kelas ibu hamil. Hal ini sesuai dengan teori yang dikemukakan Wawan, 2011, faktor-faktor yang mempengaruhi sikap adalah pengalaman pribadi, pengaruh orang lain yang dianggap penting, pengaruh budaya, media masa dan factor emosional.(Dhevy \& Marom Aufarul, 2016)

\section{Sarana dan prasarana dan pelaksanaan kelas ibu hamil.}

Hasil penelitian ini didapatkan bahwa sebesar $61,7 \%$ sarana dan prasarana dalam pelaksanaan kelas ibu hamil belum memadai, Hasil uji statistik chi-square test didapatkan hasil $\alpha=0.164>0.05$ maka tidak ada hubungan antara kelengkapan sarana dan prasarana dengan persiapan pelaksanaan kelas ibu hamil. Hal ini menjadi dapat menjadi referensi bagi pemerintah dalam meningkatkan kesehatan ibu dan anak terutama kegiatan kelas ibu perlu didukung dengan fasilitas yang memadai seperti disediakannya ruangan khusus untuk pelaksanaan kelas ibu hamil. Walaupun tidak didukung dengan kelengkapan sarana dan prasarana seperti ruangan yang besar, papan tulis, matras pelaksanaan kelas ibu hamil tetap berlangsung. Wilayah kerja Puskesmas Madapangga yang mencakup 
11 Desa pelaksanaan kelas ibu hamil hanya dilakukan 1 kali perdesa selama 1 tahun. hal ini disebabkan fasilitas yang disediakan hanya untuk melakukan 1 kali pelaksanaan kelas ibu. Selebihnya ibu hamil akan diberikan informasi melalui, bidan desa, posyandu, dan saat ibu berkunjung ke Puskesmas untuk memeriksakan kehamilannya.

Kelas ibu hamil merupakan sarana untuk belajar bersama tentang kesehatan bagi ibu hamil, dalam bentuk tatap muka dalam kelompok yang bertujuan untuk meningkatkan pengetahuan dan keterampilan ibu-ibu mengenai kehamilan, perawatan kehamilan, persalinan, perawatan nifas, perawatan bayi baru lahir, mitos, penyakit menular dan akte kelahiran. Setiap ibu hamil diwajibkan memiliki buku KIA, karena di buku ini terdapat beberapa informasi tentang kehamilan. Akan tetapi, tidak semua informasi penting termuat di buku KIA. Untuk itu, dibentuklah program Kelas Ibu Hamil.

Sarana dan prasarana.yang dibutuhkan dalam peleksanaan kelas ibu hamil adalah : Ruang belajar untuk kapasitas 10 orang peserta kira-kira ukuran 4 x 5 m, dengan ventilasi dan pencahayaan yang cukup, Alat tulis menulis (papan tulis, kertas, spidol, bolpoin) jika ada, Buku KIA, Lembar balik kelas ibu hamil, Buku pedoman pelaksanaan kelas ibu hamil, Buku pegangan fasilitator, Alat peraga (KB kit, food model, boneka, metode kanguru, dll) jika ada,Tikar/karpet (matraks), Bantal, kursi (jika ada), Buku senam hamil. (Kemenkes RI, 2014)

Hal ini sesuai dengan penelitian yang dilakukan oleh Hastuti, dkk (2011) tentang efektifitas pelatihan kelas ibu hamil di Puskesmas Tladan Kabupaten Magetan menemukan bahwa pendidikan kesehatan melalui pelatihan kelas ibu hamil efektif untuk meningkatkan pengetahuan ibu hamil mengenai perawatan seputar kehamilan Pada penelitian ini kelompok ibu yang pernah mengikuti kelas ibu hamil mendapatkan materi tentang perawatan selama kehamilan, persalinan dan nifas dari tenaga kesehatan diwilayah kerja Puskesmas Madapangga.

Kelas ibu hamil mendapatkan materi secara komprehensif tentang perawatan selama kehamilan, persalinan dan nifas dimana seluruh ibu diberikan buku panduan buku kesehatan ibu dan anak sehingga meningkatkan pengetahuan ibu. Meskipun mayoritas ibu hamil mendapat informasi adanya kelas ibu hamil dari kader posyandu tetapi tidak mengikuti kelas ibu hamil karena alasan repot. Hal ini sejalan dengan hasil penelitian Romlah (2009) yang menunjukkan bahwa pengetahuan ibu tentang perencanaan persalinan dan pencegahan komplikasi lebih baik pada ibu hamil pada daerah dengan kelas ibu hamil daripada pengetahuan ibu hamil pada daerah tanpa kelas ibu hamil.

Hasil penelitian disimpulkan bahwa pelaksanaan kelas ibu hamil sangat berpengaruh pada peningkatan pengetahuan ibu tentang perawatan selama kehamilan, persalinan dan nifas. Hal ini terjadi mungkin karena selama mengikuti kelas ibu hamil responden telah mendapatkan informasi dari tenaga kesehatan. Di dalam kelas ibu hamil responden mendapatkan penjelasan tentang pemeriksaan dan perawatan kehamilan seperti memeriksakan kehamilan ke dokter dan bidan, periksa kehamilan minimal 4 kali selama kehamilan dan kapan saja ibu harus memeriksakan kehamilannya. 


\section{PENUTUP \\ Kesimpulan}

Pelaksanaan kelas ibu hamil sangat membantu dalam memingkatkan pengetahuan ibu tentang kehamilan, persalinan dan nifas, dan ada hubungan antara pengetahuan ibu dengan persiapan pelaksanaan kelas ibu hamil, tidak ada pengaruh antara sikap ibu dengan persiapan pelaksanaan kelas ibu hamil serta tidak ada pengaruh antara sikap ibu dengan persiapan pelaksanaan kelas ibu hamil

\section{Rekomendasi}

Fasilitator kelas ibu hamil di Puskesmas Madapangga agar lebih menekankan kembali pentingnya pemeriksaan kehamilan minimal 4 kali selama kehamila, Perencanaan persalinan dan pencegahan komplikasi agar lebih mudah mendeteksi tandatanda bahya persalinan, serta pentingnya ibu hamil menghindari posisi tidur terlentang pada hamil tua, serta pemeriksaan kesehatan ibu nifas agar terdeteksi tanda-tanda bahaya pada ibu nifas.

\section{REFERENSI}

Dhevy, F. N., \& Marom Aufarul. (2016). Implementasi Program Kesehatan Ibu dan Anak Bidang Pelayanan Antenatal Care dan Nifas Di Puskesmas Bandarharjo Kota Semarang. Departemen Administrasi Publik Fakultas Ilmu Sosial Dan Ilmu Politik Universitas Diponegoro. Retrieved from https://media.neliti.com/media/publications/183671-ID-implementasi-programkesehatan-ibu-dan-a.pdf

Fuada, N., \& Setyawati, B. (2016). Pelaksanaan Kelas Ibu Hamil Di Indonesia. Jurnal $\begin{array}{lll}\text { Kesehatan } & \text { Reproduksi, }\end{array}$ https://doi.org/10.22435/kespro.v6i2.5411.67-75

Kemenkes RI. (2014). Pedoman Pelaksanaan Kelas Ibu Hamil Kemenkes RI 2009-2011. Kementrian Kesehatan RI, pp. 1-26. https://doi.org/351.077 Ind r

Lapalulu, L. S. (2018). Evaluasi pelaksanaan kelas ibu hamil di wilayah kerja puskesmas landawe kabupaten konawe utara tahun 2018. 1-121.

Naharani, A. R., Siswati, S., \& Fatkhiyah, N. (2018). Hubungan Perilaku Keikutsertaan Kelas Ibu Hamil Dengan Tingkat Kecemasan Dalam Menghadapi Persalinan Pada Ibu Hamil Primigravida Trimester Iii Di Desa Kalisapu Kecamatan Slawi. Siklus: Journal Research Midwifery Politeknik Tegal, 7(2), 300. https://doi.org/10.30591/siklus.v7i2.856

R. Oktaviance. S, L. S. (2016). Pengaruh Kelas Ibu Hamil Terhadap Pengetahuan dan Sikap Ibu Tentang Pemeriksaan dan Perawatan Kehamilan di Wilayah Kerja Puskesmas Batam. Stikes Santa Elisabeth Medan, 2016.

Ratmawati, L. A. (2018). Evaluasi program pelaksanaan kelas ibu balita di wilayah kerja dinas kesehatan kabupaten banjarnegara. Jurnal Kebidanan Dan Keperawatan Aisyiyah, 14(1), 25-31. https://doi.org/10.31101/jkk.546

Retnowati, Y., \& Sulidah. (2018). Analisis Motivasi Ibu Hamil Dalam Mengikuti Kelas Ibu Hamil Di Daerah Pesisir Wilayah Kerja Puskesmas Pantai Amal Kota Tarakan. Journal of Borneo Holistic Health, 1(2), 217-229. 